\title{
EFFECTS OF WATER CONDUCTIVITY ON MICROBUBBLE SIZE AND DISTRIBUTION FOR SEAWATER FLOTATION IN DESALINATION PRE- TREATMENT PROCESSES
}

\author{
N. MARGARIT, C. BAYONA, S. NAVEA, E. FERRERO \& J. J. MALFEITO \\ R\&D Department, Acciona Agua, Barcelona, Spain.
}

\begin{abstract}
Dissolved air flotation (DAF) technologies are commonly used in water and wastewater treatment. In particular, flotation of suspended solids to pre-treat high salinity water such as seawater is now becoming more widespread, even though conductivity effects on microbubble formation and behaviour are not yet well known. Thus, a series of experiments were conducted with artificial sea water and distilled water to study the effects of conductivity on size and flow patterns of the air bubbles inside a pilotscale DAF tank. The experimental set-up included a high-speed CCD camera to capture the generated microbubbles. Posterior image processing determined the bubble diameters. Also, fluorescein was used as a fluorescent tracer to follow flow paths. The viability of using fluorescein was first assessed at laboratory scale. The intensity of the dye was determined through molecular fluorescence as a function of the concentration using a high conductivity matrix. Furthermore, a stability study of the intensity along time was performed in order to ensure reliability of the experimental measurements. The results showed that bubble size decreased and dead areas increased when seawater was used instead of distilled water.

Keywords: DAF, desalination, flotation, fluorescein, fluorescence, microbubbles, pre-treatment, seawater
\end{abstract}

\section{INTRODUCTION}

Bubble size is a determinant parameter in dissolved air flotation (DAF) since it affects bubble-particle behaviour and interactions, such as collisions and adhesion as well as ascensional velocity [1]. Therefore, diameter knowledge of generated bubbles is an added value that could improve DAF efficiency. As long as the amount of injected air is constant, the smaller the bubbles, the more quantity of them will be present and the more effective the flotation should be.

Previous studies $[2,3]$ demonstrated that flotation performance is adequate when bubble diameters are in between 40 and $80 \mu \mathrm{m}$. Larger diameter in bubbles represents faster ascencional velocity; hence, probabilty to contact suspended solid particles and make them float is smaller. This paper analyzes water salinity as a factor that affects bubble size, since it is a physical property that modifies not only air solubility, but also superficial tension $[4,5]$. Both parameters have an effect on bubble nucleation and in result, on bubble diameter [6].

Hydraulic behaviour is another important aspect of flotation. Emplyoing the flotation volume efficiently is a requirement defined not only by the system geometry, but also by the flow properties. It is a fact that high salinity water behaves different than distilled water as it presents different physical properties. Employing a dye, fluorescein, in order to visualize flow paths of the system at different salinity conditions, is proven to provide useful flow performance information. For this reason, a method for dye quantification is developed at a laboratory scale and then used in a pilot plant to determine equipment residence time and generated dead zones as hydraulic parameters. 


\section{THEORY}

Residence time in a flotation device could be calculated by simple dividing flow rate by total volume. However, that would only be valid in a perfect plug flow situation. Instead, real equipment does not perform ideally and thus, a method to analyze flow performance is developed using fluorescein as a visual tracer and quantifying aid.

Fluorescein (see Fig. 1) is an organic substance, hydrosoluble, yellowish and fluorescent. Under light exposure, it absorbs certain wavelengths and emits fluorescent light.

The intensity of fluorescein is determined by molecular fluorescence, as a function of its concentration, in both high and low conductivity solutions (sea water or distilled water). Furthermore, a stability study of the intensity of the dye along time must be carried out in order to assure measurements reliability during the assays.

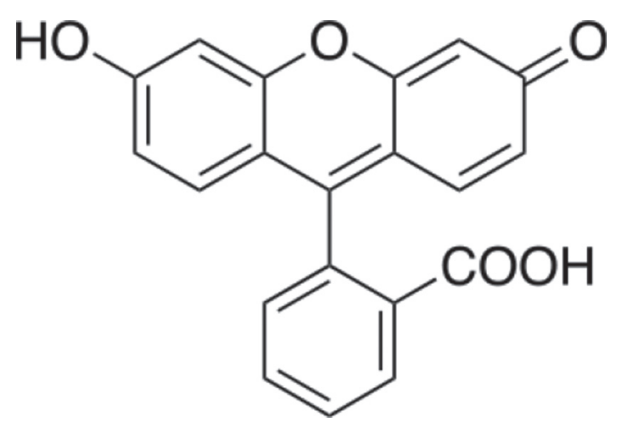

Figure 1: Fluorescein molecular structure.

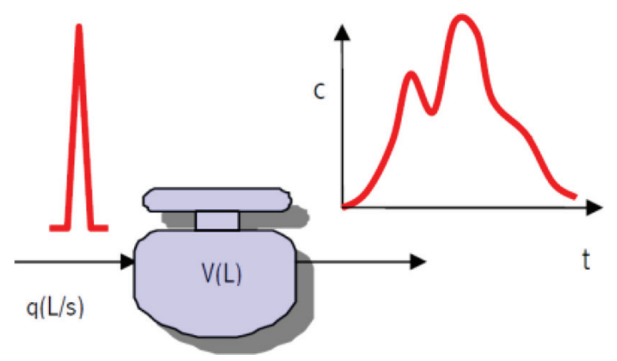

Figure 2: Stimulus-response method.

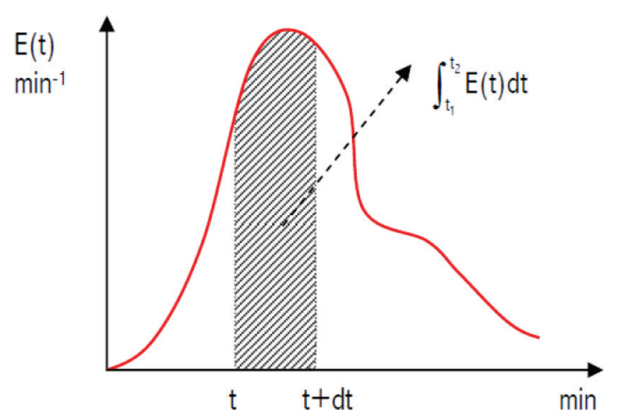

Figure 3: Residence time distribution function. 
In order to determine the system residence time, a stimulus-response method is utilized, measuring $\mathrm{c}(\mathrm{t})$ as the tracer concentration at a given instant (in this case, measured as fluorescein intensity). Experimentally, a portion of the fluid is introduced in the system at a given concentration of dye and the response (resulting dye intensity) is measured at the exit (see Fig. 2) .

The distribution function of residence time $\mathrm{E}(\mathrm{t})$ represents the probability that a fluid element entering the vessel at $\mathrm{t}=0$ exits at time $\mathrm{t}$ as it is shown in Fig. 3. Hence, it provides information on how much time the initial concentration of dye needs to go through the equipment. The area under the curve gives information on each fraction of fluid that abandons the flotation device at a given instant.

Other interesting parameters to take into account are:

- Observed residence time, $\mathrm{t}_{\mathrm{obs}}$ in eqn (1), which respresents an average of how long a portion of the fluid stays inside the system.

$$
t_{o b s}=\int t \cdot c(t) \cdot d t / \int c(t) \cdot d t
$$

- The corresponding standard deviation, $\sigma^{2}$ in eqn (2), which informs on disperion around the previous value (the smaller the deviation, the more similar to an ideal plug flow it is).

$$
\sigma^{2}=\int\left(t-t_{o b s}\right)^{2} \cdot E(t) \cdot d t
$$

- Dead volume, $\mathrm{V}_{\text {dead, }}$ in eqn (3) where $\mathrm{q}$ is the total flow rate though the flotation system.

$$
V_{\text {dead }}=V_{\text {total }}-q \cdot t_{\text {obs }}
$$

In general, the smaller the dead area, the better, since it indicates flow behaviour is close to an ideal plug flow.

\section{EXPERIMENTAL SET-UP AND METHODS}

\subsection{Bubble size determination using a CCD camera}

A flotation pilot plant (Fig. 4) consisting in a contact zone, where pressurized saturated water is injected at the bottom, and a separation zone divided by a baffle wall, is built to test salinity effects on bubble size and flow behaviour. The design water flow rate of such plant is $6 \mathrm{~m}^{3} / \mathrm{h}$. Dimensions of the vessel are approximately $0,5 \mathrm{~m}$ wide $\mathrm{x} 2 \mathrm{~m}$ length $\mathrm{x} 2 \mathrm{~m}$ height. The system is connected to a saturator through which about $10 \%$ of the water is circulated in order to dissolve air at varying pressures (from 3 to 7 bar). In order to capture generated bubbles, a digital high-resolution CCD camera, a Prosilica GC2450, with frame rate of $15 \mathrm{fps}$ and 2448 x 2050 resolution, is installed near the injection zone (see in picture below). All taken photographs are processed with Microsoft office picture manager. The diameters are measured for perfectly focused bubbles only.

\subsection{Fluorescein quantification}

Molecular fluorescein concentration as intensity is measured using a spectrofluorometer Varian Cary Eclipse, which employs quartz trays with $1 \mathrm{~cm}$ of optical path. Fluorescein is a dye that can be influenced by the matrix where it is dissolved. Hence, experimental measurements of fluorescein intensity are carried in the corresponding salinity solution. High-salinity solutions are synthesized using a laboratory recipe that simulates sea water of about $50 \mathrm{~ms}$ of conductivity. 


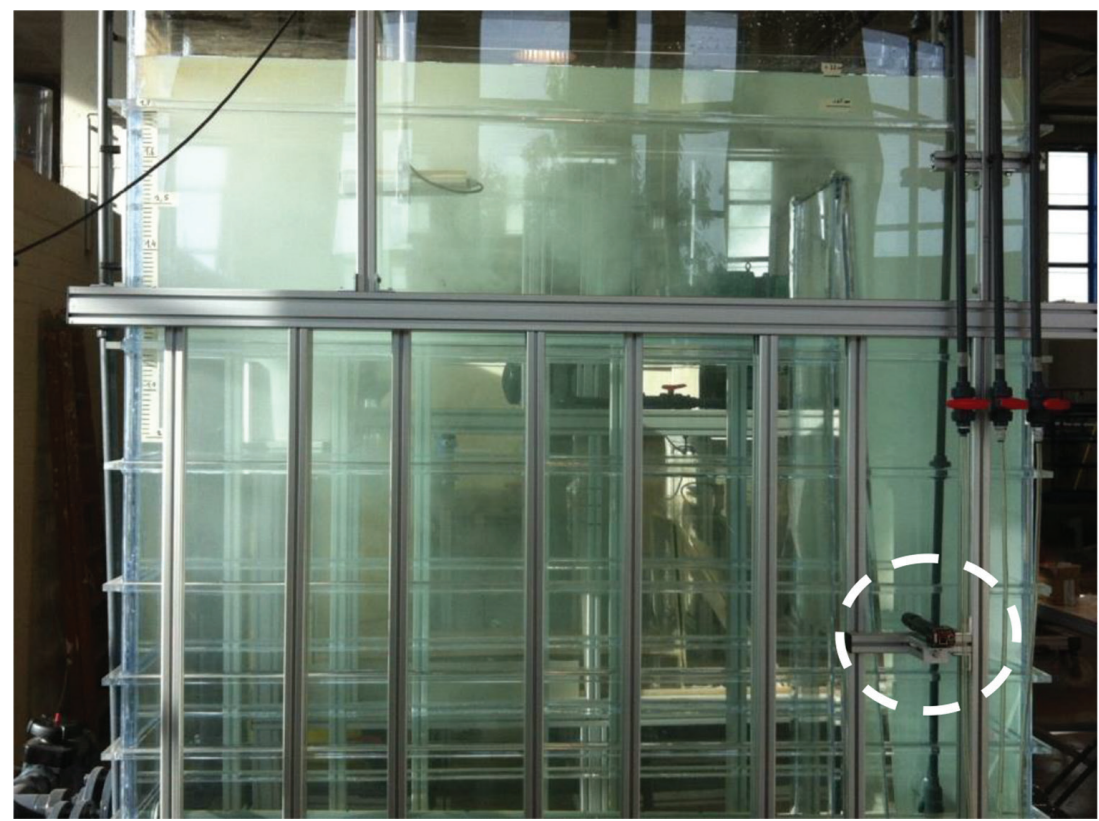

Figure 4: Flotation pilot plant.

An initial scan for excitation and emission wavelengths (Fig. 5) determines optimum values to detect fluorescence of fluorescein in high sailinity solutions.

Optimal wavelentghs found in such artificial sea water matrix are: $\lambda_{\text {excitation }}=490 \mathrm{~nm}$ and $\lambda_{\text {emission }}=512 \mathrm{~nm}$. For these values, different fluorescein concentration solutions are tested in order to generate a calibration line that allows fluorescein quantification based on
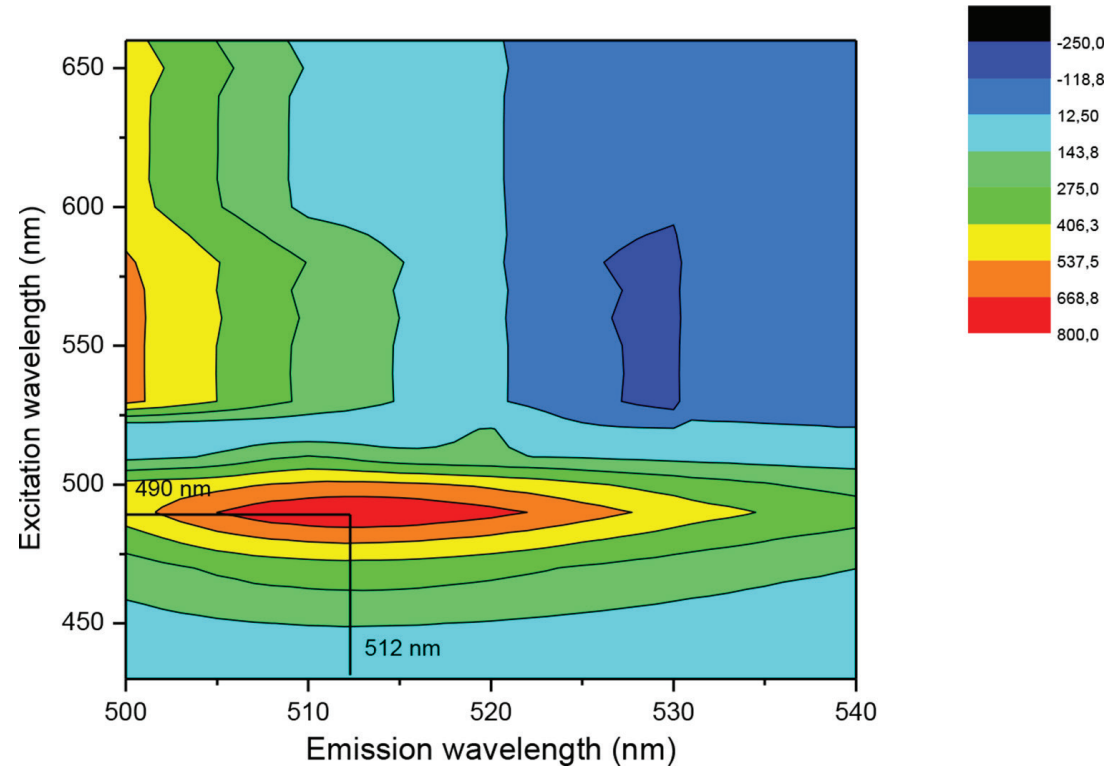

Figure 5: Excitation-emission scan for $100 \mu \mathrm{g} / \mathrm{L}$ of fluorescein. 
fluorescence intensity (represented in Fig. 6). This is afterwards used to determine flow performance inside the flotation vessel.

A stability study of fluorescein intensity along a $2 \mathrm{~h}$ period is also performed, for a high-salinity solution containing $100 \mu \mathrm{g} / \mathrm{L}$ of fluorescein (see Fig. 7). Based on the same optimal wavelengths, it is confirmed that intentisy does not decay with time.

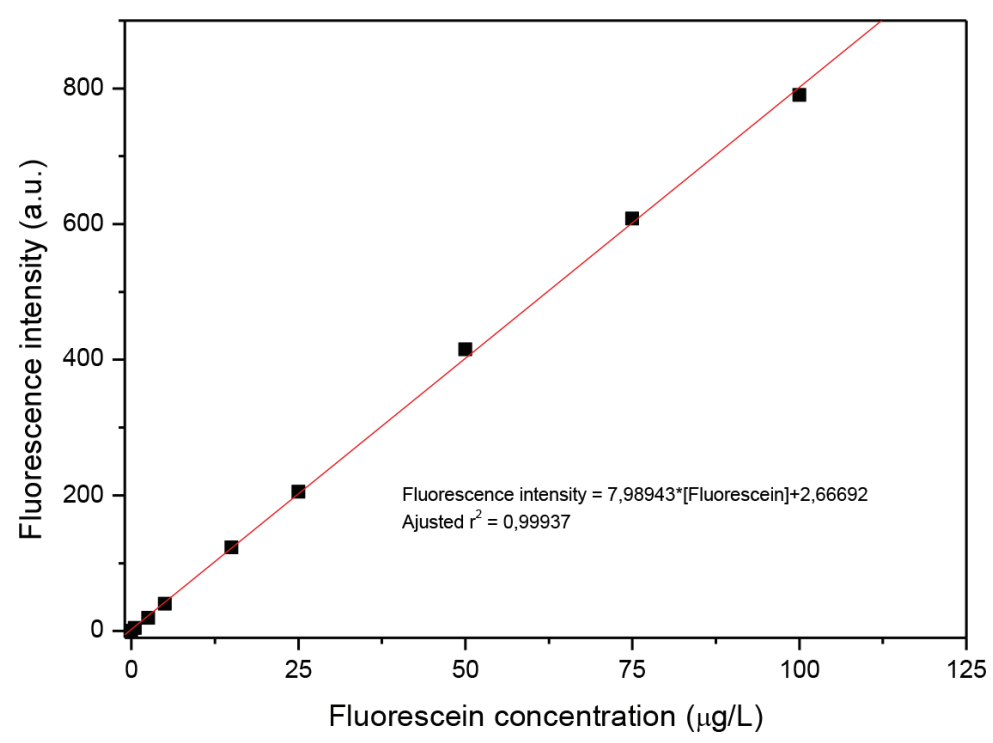

Figure 6: Fluorescein calibration line in sea water.

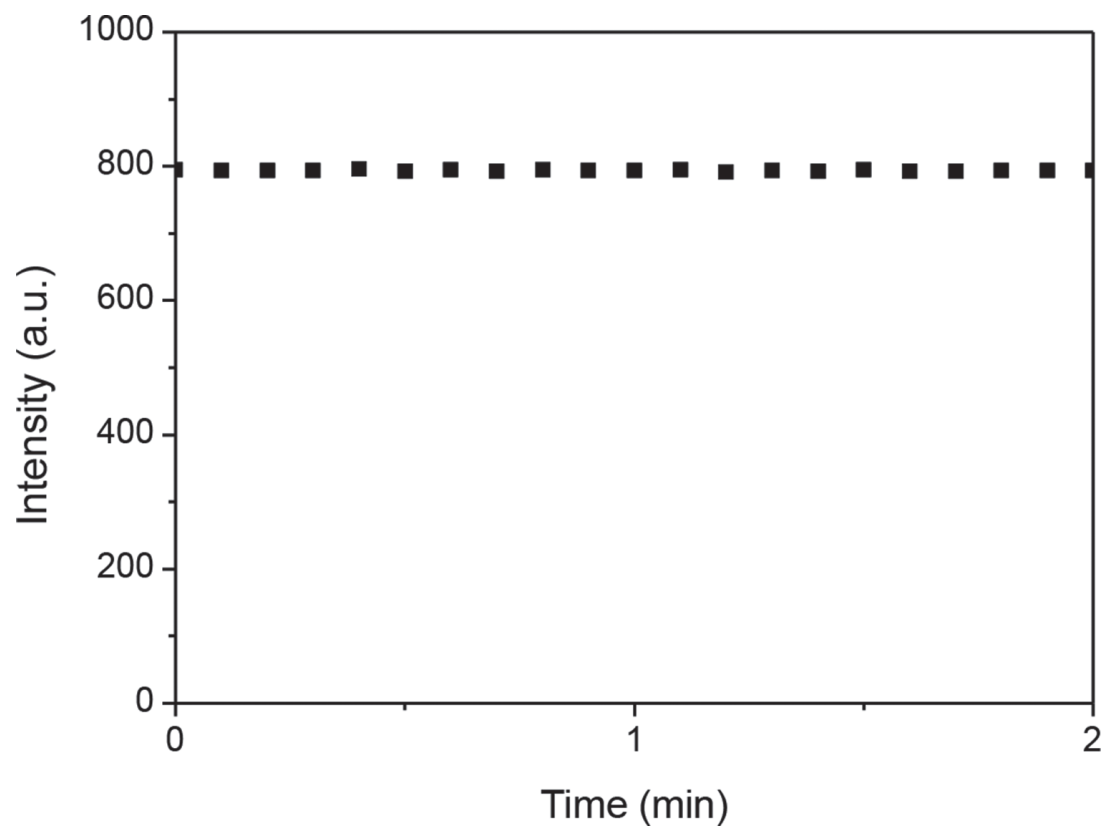

Figure 7: Fluorescein intensity along time at $490 \mathrm{~nm}$ and $100 \mu \mathrm{g} / \mathrm{L}$. 


\section{RESULTS AND DISCUSSION}

\subsection{Bubble size}

Pictures taken by a high-resolution CCD camera are analyzed to determine bubble size in a flotation pilot set-up (see example in Fig. 8). The camera located near the injection point takes images that are digitally processed. Apparent diameter is calculated from the pixels-image size relation. Different experiments at different conditions provide a range of bubble sizes that are averaged acccordingly.

\subsubsection{Distilled water bubble size}

Two different saturation pressures are used to generate bubbles using distilled water in the flotation system, 3,5 bar and 5 bar. Results are shown next in Tables 1 and 2.

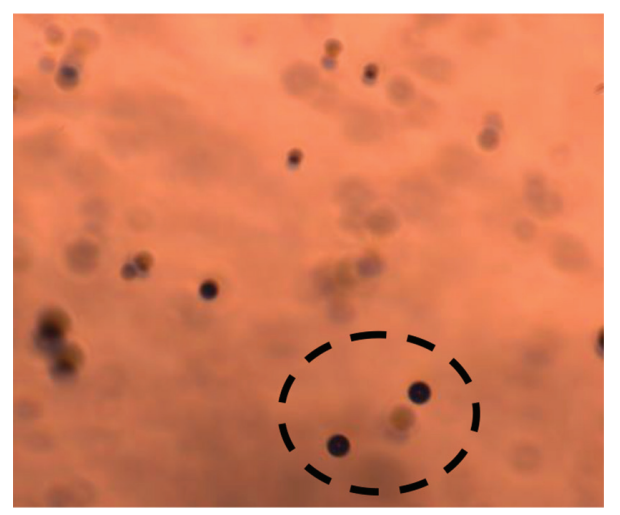

Figure 8: Perfectly focused bubbles.

Table 1: Bubble diameters in distilled water at 5 bar.

\begin{tabular}{lllll}
\hline Experiment & $\varnothing(\mu \mathrm{m})$ & Deviation $\%$ & Maximum $(\mu \mathrm{m})$ & Minimum $(\mu \mathrm{m})$ \\
\hline A & 68,60 & 13,20 & 83,36 & 51,18 \\
B & 59,74 & 15,13 & 76,05 & 45,33 \\
C & 52,27 & 19,52 & 68,00 & 35,83 \\
D & 53,25 & 16,55 & 76,05 & 38,02 \\
E & 62,83 & 16,77 & 85,55 & 43,87 \\
\hline
\end{tabular}

Table 2: Bubble diameters in distilled water at 3,5 bar.

\begin{tabular}{lllll}
\hline Experiment & $\varnothing(\mu \mathrm{m})$ & Deviation $\%$ & Maximum $(\mu \mathrm{m})$ & Minimum $(\mu \mathrm{m})$ \\
\hline A & 75,51 & 12,12 & 96,52 & 63,62 \\
B & 69,42 & 18,32 & 96,52 & 51,18 \\
C & 69,10 & 17,26 & 95,79 & 43,87 \\
D & 62,20 & 15,05 & 78,24 & 48,99 \\
E & 136,90 & 10,57 & 166,72 & 93,59 \\
\hline
\end{tabular}


At 3,5 bar, bubble sizes range from 60 to $140 \mu \mathrm{m}$ in average, while this is reduced at 5 bar, and diameters range from 50 to $70 \mu \mathrm{m}$. Hence, a benefit from using higher saturation pressures can already be noticed from this first set of experiments using distilled water. Nevertheless, at both saturation pressures, deviation is considerably large, not only among experiments, but also within the same indivual test. All deviations are well over $10 \%$ which indicates that even though most of the bubbles fall within the expected size range, there is a wide variation in size.

\subsubsection{Sea water bubble size}

For high salinity water, or the same, for a synthesized sea water matrix with about $50 \mathrm{mS}$ conductivity, a series of experiments at two different saturation pressures, 3,5 bar and 5 bar, provide a new range of bubble diameters (see results in Tables 3 and 4).

In sea water, two effects are noted. On one hand, bubble diameters are smaller than in distilled water. The average diameter ranges between $45-75 \mu \mathrm{m}$ at 3,5 bar and between 40-60 $\mu \mathrm{m}$ at 5 bar. Difference in saturation pressure is not as significant in sea water as it is in distilled water. On the other hand, deviation under these conditions appears larger than in distilled water. Almost all deviation values reach $20 \%$. However, bubble sizes fall within the appropiate flotation range, and no bubble exceeds the $100 \mu \mathrm{m}$ threshold.

\subsection{Salinity effect on flow performance}

At the working flow rate of the flotation pilot plant, experiments that analyze the intensity of fluorescein along time due to an initial disturbance are implemented (summarized in Table 5). When comparing performance for both studied salinities, observed residence time appears smaller for sea water than for distilled water, although in both cases it is aproximately $20 \%$ less than the nominal (ideal) one.

Table 3: Bubble diameters in sea water at 5 bar.

\begin{tabular}{lllll}
\hline Experiment & $\varnothing(\mu \mathrm{m})$ & Deviation $\%$ & Maximum $(\mu \mathrm{m})$ & Minimum $(\mu \mathrm{m})$ \\
\hline A & 47,01 & 15,47 & 60,69 & 35,83 \\
B & 54,11 & 19,88 & 80,43 & 38,02 \\
C & 53,93 & 29,87 & 80,43 & 25,59 \\
D & 39,45 & 24,33 & 59,23 & 21,94 \\
E & 58,50 & 18,64 & 71,66 & 38,02 \\
\hline
\end{tabular}

Table 4: Bubble diameters in sea water at 3,5 bar.

\begin{tabular}{lllll}
\hline Experiment & $\varnothing(\mu \mathrm{m})$ & Deviation $\%$ & Maximum $(\mu \mathrm{m})$ & Minimum $(\mu \mathrm{m})$ \\
\hline A & 65,81 & 11,14 & 85,55 & 50,45 \\
B & 57,00 & 13,65 & 71,66 & 40,22 \\
C & 60,20 & 15,06 & 73,85 & 43,14 \\
D & 45,90 & 23,55 & 71,66 & 29,25 \\
E & 73,75 & 21,46 & 99,44 & 36,56 \\
\hline
\end{tabular}


Table 5: Observed residence time and calculated dead volumes.

\begin{tabular}{llllll}
\hline Conditions & Water & Experiment & $\begin{array}{l}\mathrm{t}_{\mathrm{obs}} \\
(\mathrm{min})\end{array}$ & $\begin{array}{l}\sigma^{2} \\
(\mathrm{~min})\end{array}$ & $\begin{array}{l}\mathrm{V}_{\text {dead }} \\
(\mathrm{L})\end{array}$ \\
\hline $6.425 \mathrm{~L} / \mathrm{h}$ & Distilled & A & 14,97 & 4,56 & 146,69 \\
$\mathrm{t}_{\text {nom }}=18,21 \mathrm{~min}$ & & $\mathrm{~B}$ & 14,33 & 5,03 & 247,79 \\
& Sea & A & 14,26 & 2,97 & 222,48 \\
& & B & 13,30 & 3,15 & 326,11 \\
\hline
\end{tabular}

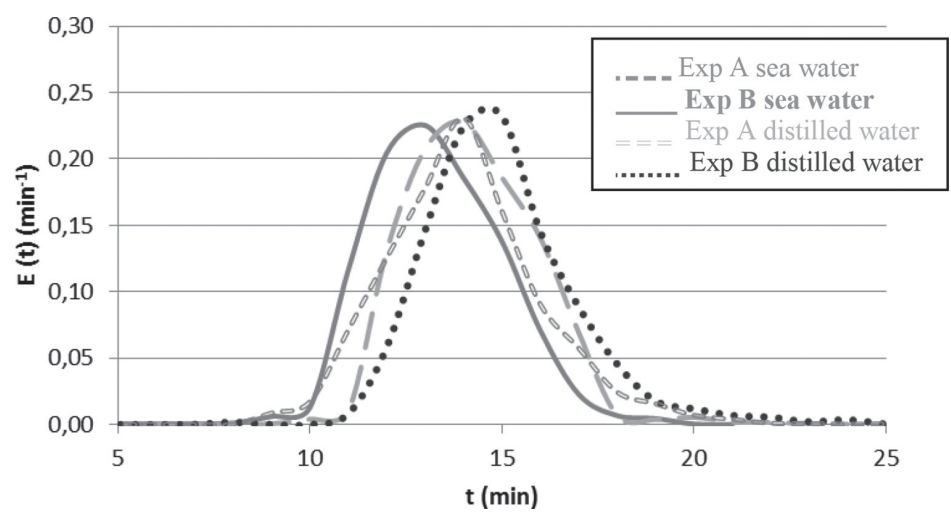

Figure 9: Distribution function for sea water and distilled water.

In result, sea water experiments show more dead zones than distilled water as it is proved in Fig. 9.

\section{CONCLUSIONS}

Experiments to study the effects of water conductivity on bubble size and flow patterns inside a pilot-scale DAF tank included a high-speed CCD camera and fluorescein as a fluorescent tracer to analyze hydraulic performance.

The intensity of the dye was determined through molecular fluorescence as a function of the concentration using a high conductivity matrix. Viability and time stability of using fluorescein as tracer were experimentally confirmed at laboratory scale.

Pilot plant results at two different saturation pressures showed that bubble size decreased when seawater was used instead of distilled water. The average bubble diameter ranged between 45 and $75 \mu \mathrm{m}$ at 3,5 bar and between 40 and $60 \mu \mathrm{m}$ at 5 bar for sea water; while bubble sizes ranged from 60 to $140 \mu \mathrm{m}$ at 3,5 bar, and between 50 and $70 \mu \mathrm{m}$ at 5 bar for distilled water. Deviation was in all cases above $10 \%$, becoming even larger for sea water experiments. Nevertheless, no bubble exceeded the $100 \mu \mathrm{m}$ threshold in high salinity conditions, while a portion of the bubbles did in distilled water.

On the other hand, calculated dead volumes increased for sea water tests compared to distilled water, resulting for the latter closer to ideal flow conditions.

In conclusion, dissolver air flotation (DAF) as a technology to pre-treat sea water is found to be appropiate in terms of generated microbubbles, which present even smaller diameters 
than those seen in non-saline water. However, general flow behavior may be affected by high salinity conditions, and less efficient separation could be observed due to larger areas of the system not being completely utilized (dead zones).

\section{BIBLIOGRAPHY}

[1] Edzwald, J.K., Dissolved air flotation and me. Water Research, 44(7), pp. 2077-2106, 2010. https://doi.org/10.1016/j.watres.2009.12.040

[2] Kwak, D.H., Jung, H-J., Kwon, S-B., Lee, E-J., Won, C-H., Lee, J-W. \& Yoo, S-J., Rise velocity verification of bubble-floc agglomerates using population balance in DAF process. The 5th International Conference on Flotation in Water and Wastewater Systems, Seoul, 2007.

[3] Zimmerman, W.B., Tesar, V., Butler, S. \& Bandulasena, H.C., Microbubble generation. Recent Patents on Engineering, 2(1), pp. 1-8, 2008. https://doi.org/10.2174/187221208783478598

[4] Edzwald, J.K. \& Haarhoff, J., Adapting dissolved air flotation for the clarification of sea water. Desalination, 311, pp. 90-94, 2013. https://doi.org/10.1016/j.desal.2012.10.035

[5] Vion, P., Pressurised water releasing nozzle for generating microbubbles in a flotation plant. US7651620 Patent, 2003.

[6] Hamme, C. \& Emerson, S.R., The solubility of neon, nitrogen and argon in distilled water and seawater. Deep Sea Research, 51(11), pp. 1517-1528, 2004.

https://doi.org/10.1016/s0967-0637(04)00119-0 